\title{
BMJ Open A register-based 13-year to 43-year follow-up of 70 patients with obsessive-compulsive disorder treated with capsulotomy
}

Christian Rück, ${ }^{1,2}$ Johan K Larsson, ${ }^{1}$ David Mataix-Cols, ${ }^{1,2}$ Rickard Ljung ${ }^{3}$

To cite: Rück C, Larsson JK, Mataix-Cols D, et al. A registerbased 13-year to 43-year follow-up of 70 patients with obsessive-compulsive disorder treated with capsulotomy. BMJ Open 2017;7:e013133. doi:10.1136/ bmjopen-2016-013133

Received 22 June 2016 Revised 27 January 2017 Accepted 3 February 2017
CrossMark

${ }^{1}$ Department of Clinical Neuroscience, Karolinska Institutet, Stockholm, Sweden ${ }^{2}$ Stockholm Health Care Services, Stockholm County Council, Stockholm, Sweden ${ }^{3}$ Institute of Environmental Medicine, Karolinska Institutet, Stockholm, Sweden

Correspondence to Dr Christian Rück; christian.ruck@ki.se

\section{ABSTRACT}

Objectives Little is known about the long-term medical status of patients with severe obsessive-compulsive disorder (OCD) undergoing capsulotomy, a neurosurgical last-resort treatment. The present study used national registers to identify all operated patients with $O C D$ in Sweden and evaluated their long-term medical status, including mortality, hospital admissions and psychotropic medication after capsulotomy for OCD.

Design Register-based long-term follow-up cohort study. Participants We used the procedural and diagnostic codes in the Swedish National Patient Register to define the study population between 1970 and March 2013. Verification by manual review of medical records of the indication for surgery in those identified by the register yielded the final study cohort of 70 patients, followed 1343 years after surgery. The sensitivity of the case selection method was $86 \%$.

Outcome measures We studied hospitalisation 5 years before and after surgery. Mortality data were derived from the Causes of Death Register. The Prescribed Drug Register was used to study psychotropic drug utilisation. Results By March 2013, 29 of the 70 patients were deceased. Their mean age at the time of death was 68 years $(S D=14)$. Two patients had committed suicide and one had died of suspected suicide. Seventy per cent had been admitted to a psychiatric ward in the 5 years preceding surgery, and $84 \%$ in the first five postoperative years. Seventy-five per cent of those alive in 2012 were prescribed at least two psychotropic medications, often at high doses, the most common being antidepressants. Conclusions Malignant OCD has a poor long-term prognosis. Patients who are candidates for surgery should be informed that, while OCD symptoms may be ameliorated with surgery, they should not expect long-term freedom from medication and psychiatric care.

Neurosurgery has long been used as a last-resort treatment for patients with severe obsessive-compulsive disorder (OCD) not responding to traditional pharmacological or psychotherapeutic treatments. While procedures such as capsulotomy and cingulotomy have been used for a number of disorders in the past, the main indication in the present day is for OCD. The neurophysiology of OCD
Strengths and limitations of this study

Largest capsulotomy-treated obsessive-compulsive disorder cohort reported so far, with follow-up time up to 43 years.

- Capsulotomy cases are identified through national registers, minimising ascertainment biases.

- Register-based outcomes such as causes of death, hospitalisations and prescription data.

- No clinical data are reported.

includes structural and functional alterations in cortico-striato-thalamic, limbic and parietal circuits. ${ }^{1-3}$ In capsulotomy, lesions are placed in the anterior limb of the internal capsules, whereas lesions in cingulotomy are placed bilaterally in the anterior cingulate gyri. The capsulotomy lesions created by the use of radiofrequency heating (thermocapsulotomy) or gamma radiation involve fibres connecting the mediodorsal thalamus and the prefrontal cortex. ${ }^{4}$ A similar target that is ablated in capsulotomy has also been the target in deep brain stimulation (DBS) protocols. ${ }^{5}$ Despite the recent rise of DBS, ablative neurosurgery is still available in centres worldwide.

The safety of neurosurgery for mental disorders has been a source of recurring controversy ${ }^{6}$ ever since the very first account of brain surgery for a psychiatric problem by the Swiss psychiatrist Burckhardt in $1889 .^{7}$ The efficacy and safety of capsulotomy in OCD have been studied in a number of case series and one randomised controlled trial. ${ }^{8}$ A Swedish long-term follow-up study by our group done 4-17 years after capsulotomy for OCD did show significant symptom reduction, but also, in a minority of patients, permanent side effects including apathy, disinhibition, weight gain and incontinence. ${ }^{9}$ Nine out of the 25 cases were in remission in the long term. Despite the improvement in 
symptom burden, the level of functioning of the patients was still low 4-17 years after surgery (mean Global Assessment of Functioning=47). Nine out of 25 patients had made suicide attempts prior and seven had done so in the follow-up period, including one completed suicide; four out of these seven patients made their first suicide attempt after surgery. Seventeen out of 23 patients alive at long-term follow-up were still receiving pharmacological treatment. In contrast, other studies have reported both high response rates and few or no side effects. ${ }^{10-13}$ In a case series of 15 patients with $\mathrm{OCD},{ }^{10}$ capsulotomy did produce a large reduction in OCD symptoms (at least $50 \%$ OCD symptom decrease in 29\%), but although global functioning increased after surgery, it still remained relatively low at the last follow-up (Global Assessment of Functioning=53). A more recent Canadian study of 19 cases reported a response rate of $37 \%$, but functioning, suicide attempts and current medication were not reported. ${ }^{14}$ The largest case series of OCD capsulotomy so far, conducted in China and including 53 patients, reported unusually high remission rates $(38 \%$ were symptom-free at follow-up). ${ }^{15}$ However, it is unclear how many of the patients included in that study could really be considered treatment-refractory because they had not received cognitive behaviour therapy and/or an appropriate course of antiobsessive medication. No information on functioning, suicide attempts or medication at follow-up was provided.

In the only randomised controlled trial to date, 16 participants were randomised to gamma ventral capsulotomy or sham surgery, with no statistically significant differences in outcome between the two groups on the primary endpoint (2 vs 0 responders in the capsulotomy vs sham groups at 1-year follow-up, respectively). ${ }^{16} 17$ After the blind was broken, four of the sham surgery patients underwent gamma ventral capsulotomy and were followed for up to 36 months. At the last unblinded follow-up reported (after more than 4 years from inclusion), 7 of the 12 patients (58\%) who underwent capsulotomy had responded versus 0 of 4 who did not undergo the procedure. Visuospatial memory improved in the active surgery group, while it remained stable in the sham group; no decline in cognitive or motor functioning was observed at 1-year follow-up. ${ }^{18}$ The most serious adverse event was an asymptomatic radiation-induced cyst in one patient. ${ }^{16}$

Long-term follow-ups of capsulotomy-treated patients are extremely rare and potentially biased, as patients are followed up and evaluated by the same treating clinicians. In the present study, we aimed to take advantage of the unique Swedish national registers to identify a cohort of all patients with OCD who have underwent capsulotomy in Sweden since 1970. Specifically, we examined long-term medical status and functioning of these patients, as measured by mortality rates, hospital admissions and psychotropic medication use using register data.

\section{METHODS}

This population-based cohort study is based on information from three Swedish population health registers. We used the procedural and diagnostic codes of capsulotomy in the Swedish National Patient Register to define the study population between 1970 and 2007. Verification by manual review of medical records of the indication for surgery in those identified by the register yielded the final study cohort of 70 patients, followed 13-43 years after surgery. We followed the cohort for psychiatric hospitalisation around the time of capsulotomy, subsequent psychotropic medication and death. Information on endpoints was retrieved from national register with different availability of data: the Swedish Prescribed Drug Register (2006-2012) and the National Causes of Death Register (1970-2013), in addition to the National Patient Register (hospitalisations up to 5 years after surgery). Linkage between these registers is possible by the unique personal identity number assigned at birth to each resident in Sweden. ${ }^{17}$ The study was approved by the regional ethics board in Stockholm, Sweden (D-nr 2011/10-32). The ethical approval did not allow for in-person follow-up, and therefore more detailed clinical data, such as OCD symptom severity, could not be obtained.

\section{Definition of study population}

The National Patient Register was started in 1964 and has nationwide coverage on psychiatric inpatient care since 1973, and partial coverage of somatic care. ${ }^{19}$ Since 1987 the register has full coverage of both psychiatric and somatic inpatient care. The register also covers all patients in specialised somatic and psychiatric outpatient care since 2001. For each patient, characteristics of the admission, for example, hospital, clinic, ward, date of admission and discharge, main diagnosis and secondary diagnoses at discharge, operational codes, and dates of operation, are recorded in addition to age, sex and place of residence. The validity of the OCD diagnoses in the register has recently been shown to have reasonable reliability and validity. ${ }^{20}$

Personal identification numbers for all persons registered in the Swedish National Patient Register from 1970 until 2007 with a surgical procedure code indicating capsulotomy or related procedures (the Swedish version of the Nordic Classification of Surgical Procedures: 6th version: 0110 (stereotactic lesion, destruction of nucleus or nerve tract), 0238 (other similar operations, other operations on brain), 0142 (radical extirpation) and 0233 (stereotactic technique, other operations on brain); revised version 2004: AAG10 (stereotactic destruction of nucleus or nerve tract), AAG50 (stereotactic radiation) and AAG99 (other stereotactic operation) ) and an International Statistical Classification of Diseases and Related Health Problems (ICD) code for any psychiatric disorder (ICD 8 300.30, ICD 9 290-319 and ICD 10F01-99) were retrieved from the National Patient Register. ${ }^{21} 22$ Procedure and diagnostic codes were chosen to be overinclusive as we were to 


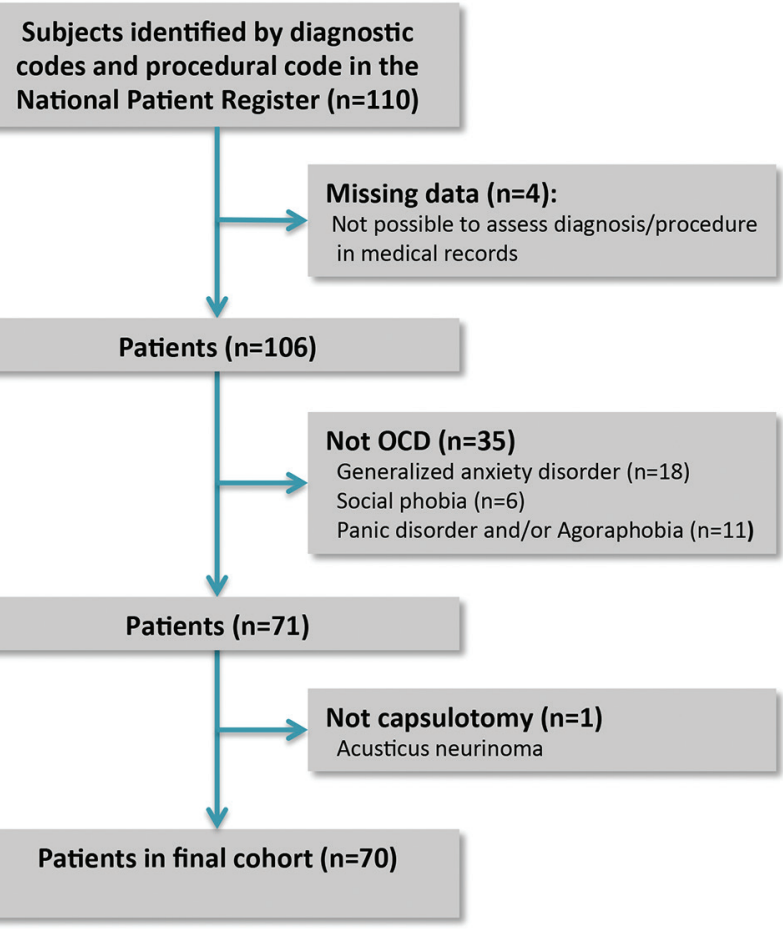

Figure 1 Flow chart of the identification of final study cohort using medical records.

validate all codes through manual review of the medical records. The National Patient Register also holds information on what hospital performed the surgery, and all patients in this study were operated on at the Karolinska University Hospital in Solna, Sweden. In total, 110 subjects had a psychiatric diagnosis and had neurosurgery and constituted our study population. We requested medical records for the study population to verify (1) that the surgical procedure was capsulotomy and (2) that the indication for surgery was OCD. Review of the medical records by one psychiatrist (JKL) yielded the final study cohort of 70 patients, with verified capsulotomy with OCD as the indication for surgery. Details of the sample selection are shown in figure 1 .

As a control of the sensitivity of our case identification method, we used an already published case series that was operated on during the same time and at the same hospital. These patients should be expected to be in the National Patient Register and therefore be identified here. $^{9}$

The study population was followed from 1 January 2006 until December 2012 with respect to psychotropic medication and from date of capsulotomy until March 2013 with respect to death.

\section{Psychiatric and somatic care before and after capsulotomy}

We studied the utilisation of somatic and psychiatric care 5 years before and 5 years after surgery. Psychiatric care was defined as an admission with a psychiatric disease as main diagnosis (ICD8 and ICD9: 290-319ZZ, ICD10: F00-F99). Hospitalisation for suicide attempt (ICD8 and ICD9: E950-E959, ICD $10 \times 60-X 84)$ or unclear intent (ICD8 and ICD9: E980-E989, ICD10: Y10-Y34) was also studied. Suicide attempts that did not lead to hospitalisation were not included as the outpatient care was not included in the National Patient Register until 2001. Somatic care was defined as any other hospitalisation without a psychiatric disease as main diagnosis. The hospitalisation at surgery was excluded from the analyses.

\section{Mortality}

Data on mortality were derived from the Causes of Death Register, which contains all deaths of Swedish residents since $1961 .{ }^{23}$ For each death, subject characteristics (date of death, underlying cause of death, nature of the injury, multiple causes of death, marked if autopsied or not) were retrieved. The completeness of the register is high, with only $1 \%-2 \%$ of deaths lacking underlying cause of death. $^{23}$

\section{Psychotropic medication}

The Swedish Prescribed Drug Register contains all filled prescriptions in Sweden. ${ }^{24}$ Updated monthly, there are presently approximately 95 million prescriptions per year. Each record contains the Anatomical Therapeutic Chemical (ATC) classification, ${ }^{25}$ and information on dose, amount, date of expenditure and prescriber characteristics. Before 1 July 2005 the personal identity number was not recorded; hence, it is not possible to study drug consumption before that date. By linkage between the patient register and the Prescribed Drug Register, we were able to study drug utilisation between 2006 and 2012 (to allow for at least 1-year follow-up until the end of the study period). Drugs were grouped according to the ATC classification system. We studied filled prescriptions of antiepileptics (ATC N03), antipsychotics (N05A), anxiolytics (N05B), hypnotics and sedatives (N05C), and antidepressants (N06A).

\section{Statistical analyses}

Age was presented as mean age with SD and range. Hospitalisations were presented as mean number of hospitalisations and, for those with at least one hospitalisation, range. Daily defined dose (DDD) of a drug is the standard daily treatment dose for an average patient. A prescription with a DDD of 100 indicates that the drug will last for a treatment period of 100 days if the dose is the standard dose. DDD is presented as median DDD and information on first and third quartiles in a calendar year of those with at least one filled prescription of each class of drug, respectively, during that year. A DDD of 365 implies that on average the patients are on standard dose daily during the whole year. A DDD of 730 implies double-standard dose daily. A DDD of 182 implies half-standard dose daily or a shorter period on standard dose.

All statistical analyses were performed with SAS software EG V.4.3. 
Table 1 Characteristics of 70 patients undergoing capsulotomy for obsessive-compulsory disorder in Sweden, 1970-2000

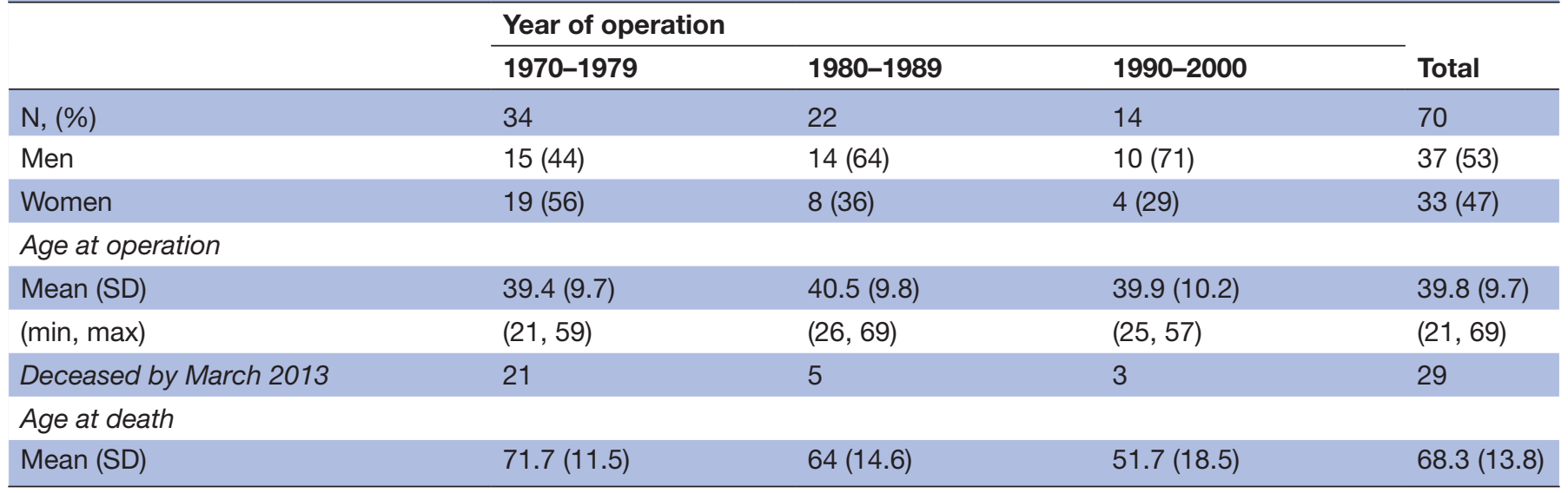

\section{RESULTS}

\section{Sensitivity of case identification method}

Our 70 subjects identified via registers were matched with the published case series of 25 patients with OCD undergoing capsulotomy at the Karolinska University Hospital from 1988 to $2000 .{ }^{9}$ Twenty one out of these 25 cases were also in our current study population, a sensitivity of $86 \%$.

\section{Characteristics of the cohort}

Basic characteristics of the sample are shown in table 1 . As can been seen, the number of OCD cases undergoing capsulotomy at Karolinska Hospital has decreased for every decade and the latest capsulotomy was performed in 2000.

Out of the 70 patents, 54 underwent thermocapsulotomy ( 44 bilateral, 4 unilateral and 6 of unknown laterality) and 16 received gamma capsulotomy with the Leksell Gamma Knife (14 bilateral and 2 unknown laterality). Seven patients who had been operated with thermocapsulotomy underwent the same procedure again, and five patients who had been subjected to gamma knife surgery were reoperated.

\section{Mortality, suicide and suicide attempts}

By March 2013, 29 of the 70 patients were deceased. Their mean age at the time of death was 68 years $(\mathrm{SD}=14)$. During follow-up two subjects had committed suicide. A third subject had drowned and in the Causes of Death Register it was deemed to be of undetermined intent, but given the background of this case with long-standing suicidality it seems likely that it was a suicide. One patient was murdered. Due to a lag in update of the Causes of Death Register, we only have date of death, and not the underlying cause of death for three deceased patients. Other causes of death were dementia $(n=2)$, diabetes $(n=2)$, suffocation by food $(n=2)$, myocardial infraction $(n=2)$, Alzheimer dementia $(n=1)$, stroke $(n=1)$, ischaemic stroke $(\mathrm{n}=1)$, spinal atrophy $(\mathrm{n}=1)$, myocarditis $(n=1)$, alcohol cirrhosis $(n=1)$, ischaemic heart disease $(\mathrm{n}=1)$, atrial fibrillation $(\mathrm{n}=1)$, cardiomegaly $(\mathrm{n}=1)$, lung oedema $(n=1)$, cancer $(n=1)$, leukaemia $(n=1)$, influenza $(\mathrm{n}=1)$ and unknown cause $(\mathrm{n}=1)$.

The number of suicide attempts recorded in the patient registry decreased slightly from before to after surgery (table 2).

\section{Hospital admissions}

The number of admissions for inpatient treatment, both somatic and psychiatric, was measured for 5 years before and after surgery, and the results are displayed in table 2. The mean number of psychiatric hospitalisations was similar before and after surgery. Seventy per cent had been admitted to a psychiatric ward in the 5 years

Table 2 Hospitalisations within 5 years before and after capsulotomy in 70 patients with OCD

\begin{tabular}{|c|c|c|c|c|}
\hline & \multicolumn{4}{|c|}{ Hospitalisations before and after operation } \\
\hline & \multicolumn{2}{|c|}{ Within 5 years before } & \multicolumn{2}{|c|}{ Within 5 years after } \\
\hline & $\mathbf{N}$ & Mean (range) & $\mathbf{N}$ & Mean (range) \\
\hline Any hospitalisation & 59 & $5.17(1-21)$ & 61 & $5.75(1-26)$ \\
\hline Psychiatric hospitalisation & 49 & $4.45(1-17)$ & 59 & $4.78(1-23)$ \\
\hline Suicide attempt & 7 & - & 2 & - \\
\hline Unclear intent (possible suicide attempt) & 3 & - & 1 & - \\
\hline
\end{tabular}

Number of patients with at least one hospitalisation $(\mathrm{N})$, mean number of hospitalisations, and minimum and maximum number of hospitalisations per patient. The hospitalisation at surgery has been excluded.

OCD, obsessive-compulsive disorder. 
Table 3 Prescribed drugs in 2006-2012 for 70 patients operated with capsulotomy in 1971-2000, in Sweden

\begin{tabular}{|c|c|c|c|c|c|c|c|}
\hline & Year & & & & & & \\
\hline & 2006 & 2007 & 2008 & 2009 & 2010 & 2011 & 2012 \\
\hline Total alive & 56 & 52 & 51 & 49 & 47 & 47 & 44 \\
\hline Antiepileptics & & & & & & & \\
\hline $\mathrm{N}$ & 10 & 11 & 9 & 10 & 9 & 10 & 11 \\
\hline Median DDD & 213 & 159 & 194 & 145 & 131 & 113 & 46 \\
\hline Q1, Q3 & $(46,240)$ & $(46,293)$ & $(93,240)$ & $(47,240)$ & $(91,191)$ & $(45,240)$ & $(28,192)$ \\
\hline Benzodiazepine & & & & & & & \\
\hline $\mathrm{N}$ & 29 & 26 & 26 & 22 & 21 & 22 & 21 \\
\hline Median DDD & 300 & 310 & 253 & 250 & 235 & 232 & 200 \\
\hline Q1, Q3 & $(50,617)$ & $(78,759)$ & $(50,829)$ & $(75,900)$ & $(110,1080)$ & $(68,900)$ & $(100,826)$ \\
\hline Antipsychotics & & & & & & & \\
\hline $\mathrm{N}$ & 12 & 14 & 11 & 12 & 13 & 12 & 13 \\
\hline Median DDD & 134 & 163 & 168 & 117 & 133 & 125 & 131 \\
\hline Q1, Q3 & $(34,318)$ & $(30,307)$ & $(70,299)$ & $(68,270)$ & $(70,183)$ & $(52,302)$ & $(54,243)$ \\
\hline Hypnotics and s & & & & & & & \\
\hline $\mathrm{N}$ & 31 & 28 & 30 & 29 & 28 & 26 & 26 \\
\hline Median DDD & 400 & 419 & 389 & 400 & 369 & 406 & 382 \\
\hline Q1, Q3 & $(200,660)$ & $(273,838)$ & $(190,800)$ & $(250,700)$ & $(165,710)$ & $(267,1065)$ & $(250,752)$ \\
\hline Antidepressants & & & & & & & \\
\hline $\mathrm{N}$ & 35 & 37 & 33 & 32 & 31 & 29 & 31 \\
\hline Median DDD & 739 & 658 & 750 & 575 & 600 & 550 & 600 \\
\hline Q1, Q3 & $(450,997)$ & $(364,990)$ & $(444,1092)$ & $(384,1003)$ & $(364,1012)$ & $(400,974)$ & $(350,911)$ \\
\hline Number of drug & & & & & & & \\
\hline 0 & 10 & 6 & 6 & 6 & 7 & 8 & 6 \\
\hline 1 & 10 & 11 & 11 & 11 & 8 & 7 & 5 \\
\hline 2 & 11 & 11 & 12 & 13 & 12 & 14 & 14 \\
\hline 3 & 17 & 15 & 15 & 10 & 12 & 9 & 9 \\
\hline 4 & 6 & 7 & 6 & 7 & 6 & 8 & 8 \\
\hline 5 & 2 & 2 & 1 & 2 & 2 & 1 & 2 \\
\hline
\end{tabular}

The number of patients on the specific class of drugs (N), and the median daily defined dose (DDD) and the 25th percentile (Q1) and 75th percentile (Q3) for those on that drug. A DDD of 365 implies that on average the patients are on standard dose daily during the whole year. A DDD of 730 implies double-standard dose daily. A DDD of 182 implies for example halved-standard dose daily or a shorter period on standard dose.

preceding surgery, and $84 \%$ in the first five postoperative years (excluding hospitalisations at surgery).

\section{Medication in the long term}

The use of prescribed medications from 2006 to 2012 is displayed in table 3 . Over $80 \%$ of patients were using psychotropic medication in the long term, the most common being antidepressants (ATC N06A). Of the antidepressants around $50 \%$ were fluoxetine and citalopram, $40 \%$ clomipramine and amitriptyline, and $10 \%$ venlafaxine and duloxetine. The DDDs for antidepressants were approximately double of the recommended starting doses (starting dose of, eg, sertraline is $50 \mathrm{mg}$ ). The low DDD for antipsychotics (ATC N05A) may suggest that the indication for its use is OCD rather than a psychotic disorder. Oxazepam was by far the most common anxiolytic (N05B). Zopiclone was the most common hypnotic/ sedative (sleeping pill (N05C)). As displayed in table 3, most subjects $(75 \%$ in 2012) took at least two different types of medication.

\section{DISCUSSION}

This study aimed to evaluate the long-term medical status of a national cohort of patients with OCD who underwent capsulotomy in Sweden, identified in national registers. Our results suggest that the 70 identified patients with OCD undergoing capsulotomy required psychiatric treatment many years after surgery and that most were prescribed multiple psychotropic medications in the 
long term, often at high doses. Strengths of the study were the nearly complete coverage of cases, the high validity and reliability of the OCD diagnostic codes, the uniquely long follow-up, and the fact that the investigators were not involved in the selection or treatment of the patients, resulting in minimal ascertainment biases.

As the study exposure is very rare, any analysis may suffer from random variation. Hence, it is not meaningful to present statistical measures of the risk of suicide, suicide attempts and life expectancy compared with the general population. In our cohort, the average age at death was 68 years. The remaining life expectancy for a 50-year-old in Sweden in 2015 was 35 years for women and 32 for men. The corresponding figures were, respectively, 33 and 29 in the beginning of the 2000s, 32 and 28 in the 1990s, 31 and 26 in the 1980s, and 30 and 26 in the 1970s. ${ }^{26}{ }^{27}$ Although not exactly comparable with the remaining life expectancy at 50 , the average age at death of the study subjects indicates a shorter life expectancy compared with the general Swedish population, in line with what has been found in other psychiatric disorders such as schizophrenia. ${ }^{28}$

During follow-up, 3 of our 70 (4.3\%) patients committed suicide. A recent study showed that 545 out of $36788(1.48 \%)$ individuals with an ICD code for OCD in the National Patient Register had committed suicide over a 44 -year period. ${ }^{29}$ Taken together, these findings highlight that more attention needs to be given to the issue of suicide in OCD, particularly in complex, treatment-resistant cases.

Our results show that most subjects still were taking multiple psychotropic medications in the long term, often in high doses, suggesting that full remission was rare and that pharmacotherapy was similar to results of the prescription for OCD in Sweden in general. ${ }^{30}$ While we cannot establish what the indication for the medication was, it seems reasonable to assume that for the most part it is related to the original surgical indication.

Limitations of the study include the lack of detailed clinical data such as symptom ratings or any other insight into the experiences of subjects. While we aimed a full coverage of all operated patients with OCD, our sensitivity analyses suggest that a limited number of cases $(14 \%)$ could not be identified in the registers with the diagnostic and procedural codes. This could be due to a number of reasons, including that appropriate codes were not used or that the codes were not transferred to the register. As this study was uncontrolled, we cannot determine to what extent the state in the long term was caused by the surgical procedure, the illness or other factors. Furthermore, the generalisability to other capsulotomy cohorts may be limited by differences in surgical technique, patient selection and what other postoperative treatments are offered. Follow-up of other cohorts will eventually provide a more comprehensive picture of the clinical status of these patients in the long term.

To conclude, our results suggest that malignant OCD has a poor long-term prognosis. Patients who are candidates for surgery and their relatives should be informed that, while OCD symptoms may be ameliorated with surgery, they should not expect long-term freedom from medication and psychiatric care. They also indicate that patients with severe, malignant OCD require close monitoring and follow-up by a specialist OCD team to minimise morbidity and mortality in this at-risk group.

Contributors $\mathrm{CR}$ and $\mathrm{RL}$ had the original idea for the study and designed the study. $\mathrm{CR}$, JKL and RL were responsible for the acquisition of the data. CR and JKL carried out the manual review of medical records to validate diagnoses. All authors carried out the statistical analysis and interpretation. CR drafted the manuscript, which was revised by all authors. All authors agree to be accountable for all aspects of the work in ensuring that questions related to the accuracy or integrity of any part of the work are appropriately investigated and resolved.

Competing interests None declared.

Ethics approval Regional Ethical Review Board Stockholm.

Provenance and peer review Not commissioned; externally peer reviewed.

Data sharing statement No additional data available.

Open Access This is an Open Access article distributed in accordance with the Creative Commons Attribution Non Commercial (CC BY-NC 4.0) license, which permits others to distribute, remix, adapt, build upon this work non-commercially, and license their derivative works on different terms, provided the original work is properly cited and the use is non-commercial. See: http://creativecommons.org/ licenses/by-nc/4.0/

(C) Article author(s) (or their employer(s) unless otherwise stated in the text of the article) 2017. All rights reserved. No commercial use is permitted unless otherwise expressly granted.

\section{REFERENCES}

1. de Wit SJ, Alonso P, Schweren L, et al. Multicenter voxel-based morphometry mega-analysis of structural brain scans in obsessivecompulsive disorder. Am J Psychiatry 2014;171:340-9.

2. Radua J, Grau M, van den Heuvel OA, et al. Multimodal voxel-based meta-analysis of white matter abnormalities in obsessive-compulsive disorder. Neuropsychopharmacology 2014;39:1547-57.

3. Radua J, van den Heuvel OA, Surguladze S, et al. Meta-analytical comparison of voxel-based morphometry studies in obsessivecompulsive disorder vs other anxiety disorders. Arch Gen Psychiatry 2010;67:701-11.

4. Axer $\mathrm{H}$, Keyserlingk DG. Mapping of fiber orientation in human internal capsule by means of polarized light and confocal scanning laser microscopy. J Neurosci Methods 2000;94:165-75.

5. Greenberg BD, Gabriels LA, Malone DA, et al. Deep brain stimulation of the ventral internal capsule/ventral striatum for obsessivecompulsive disorder: worldwide experience. Mol Psychiatry 2010;15:64-79.

6. Bejerot S. Psychosurgery for obsessive-compulsive disorder -concerns remain. Acta Psychiatr Scand 2003;107:241-3.

7. Berrios GE. The origins of psychosurgery: shaw, Burckhardt and moniz. Hist Psychiatry 1997;8:061-81.

8. Brown LT, Mikell CB, Youngerman BE, et al. Dorsal anterior cingulotomy and anterior capsulotomy for severe, refractory obsessive-compulsive disorder: a systematic review of observational studies. J Neurosurg 2016;124:77-89.

9. Rück C, Karlsson A, Steele JD, et al. Capsulotomy for obsessivecompulsive disorder: long-term follow-up of 25 patients. Arch Gen Psychiatry 2008;65:914-21.

10. Oliver B, Gascón J, Aparicio A, et al. Bilateral anterior capsulotomy for refractory obsessive-compulsive disorders. Stereotact Funct Neurosurg 2003;81:90-5.

11. Kondziolka D, Flickinger JC, Hudak R. Results following gamma knife radiosurgical anterior capsulotomies for obsessive compulsive disorder. Neurosurgery 2011;68:28-33. discussion 23-3.

12. Csigó K, Harsányi A, Demeter G, et al. Long-term follow-up of patients with obsessive-compulsive disorder treated by anterior capsulotomy: a neuropsychological study. J Affect Disord 2010;126:198-205. 
13. Sheehan JP, Patterson G, Schlesinger D, et al. $\gamma$ knife surgery anterior capsulotomy for severe and refractory obsessive-compulsive disorder. J Neurosurg 2013;119:1112-8.

14. D'Astous M, Cottin S, Roy M, et al. Bilateral stereotactic anterior capsulotomy for obsessive-compulsive disorder: long-term followup. J Neurol Neurosurg Psychiatry 2013;84:1208-13.

15. Zhan S, Liu W, Li D, et al. Long-term follow-up of bilateral anterior capsulotomy in patients with refractory obsessive-compulsive disorder. Clin Neurol Neurosurg 2014;119:91-5.

16. Lopes AC, Greenberg BD, Canteras MM, et al. Gamma ventral capsulotomy for obsessive-compulsive disorder: a randomized clinical trial. JAMA Psychiatry 2014;71:1066-76.

17. Lopes AC, Greenberg BD, Pereira CA, et al. Gamma ventral capsulotomy for obsessive-compulsive disorder: a randomized clinical trial. JAMA psychiatry. 2014;71(9):1066-1076. JAMA Psychiatry 2015;72:1258.

18. Batistuzzo MC, Hoexter MQ, Taub A, et al. Visuospatial memory improvement after gamma ventral capsulotomy in treatment refractory Obsessive-Compulsive disorder patients. Neuropsychopharmacology 2015;40:1837-45.

19. Ludvigsson JF, Andersson E, Ekbom A, et al. External review and validation of the swedish national inpatient register. BMC Public Health 2011;11:450.

20. Rück $\mathrm{C}$, Larsson $\mathrm{KJ}$, Lind $\mathrm{K}$, et al. Validity and reliability of chronic tic disorder and obsessive-compulsive disorder diagnoses in the swedish national patient register. BMJ Open 2015;5:e007520.

21. Socialstyrelsen S. Klassifikation av operationer. 6., (rev.) uppl. ed. Stockholm: Socialstyr: Allmänna förl, 1989.
22. Socialstyrelsen S. Klassifikation av kirurgiska åtgärder 1997 reviderad November 2004. 2. uppl. ed. Stockholm: Socialstyrelsen, 2004:301s.

23. The national board of health and welfare. cause of death register. 2014 http://www.socialstyrelsen.se/register/dodsorsaksregistret (accessed Jan 13)

24. Wettermark B, Hammar N, Fored CM, et al. The new swedish prescribed drug register--opportunities for pharmacoepidemiological research and experience from the first six months. Pharmacoepidemiol Drug Saf 2007;16:726-35.

25. ATC index. WHO collaborating centre for drug statistics methodology.. 2014 http://www.whocc.no/atc_ddd_index/ (accessed Jan 13 2014)

26. Statistics Sweden. Database on life expectancy. http://www. statistikdatabasen.scb.se/pxweb/en/ssd/START_BE_BE0101_ BE0101l/MedellivslangdL/?rxid=9bddcef2-61fa-46ae-bea90d4a2cd08d8b (Accessed 8 Dec 2015).

27. Sverige Statistiska centralbyrån. Livslängden i Sverige 2001-2010 : livslängdstabeller för riket och länen = [Life expectancy in Sweden 2001-2010: life tables for the country and by county]. Stockholm: Statistiska centralbyrån, 2011

28. Osby U, Correia N, Brandt L, et al. Mortality and causes of death in schizophrenia in Stockholm county, Sweden. Schizophr Res 2000;45:21-8.

29. Fernández de la Cruz L, Rydell $M$, Runeson B, et al. Suicide in obsessive-compulsive disorder: a population-based study of 36788 Swedish patients. Mol Psychiatry 2016.

30. Isomura K, Nordsletten AE, Rück C, et al. Pharmacoepidemiology of obsessive-compulsive disorder: a swedish nationwide cohort study. Eur Neuropsychopharmacol 2016;26:693-704. 